\title{
Linguistic Stylistic Analysis of Instagram Poems by Rupi Kaur, Dhiman, and R.M Drake
}

\author{
Livia Ayudita Wiadji, Sharifah Hanidar* \\ English Department, Universitas Gadjah Mada, Indonesia \\ *Corresponding Author: sharifah@ugm.ac.id
}

\begin{abstract}
In the era of digitalization, poems are also published on the internet. Instagram is one of many platforms to introduce self-written poems to a broader range of readers around the world. An Instagram poem has its own writing style and aesthetics since it is written in the modern era. In this research, stylistic analysis is used to analyze the style used in Instagram poems. Rupi Kaur, Dhiman, and R. M. Drake are three Instagram poets whose poems are chosen for analysis. The poems are chosen based on the number of likes. Five most liked poems of each poet written in 2018 are the main data source used in this research. The purpose of the research is to identify the linguistic features found in poems written by Rupi Kaur, Dhiman, and R.M Drake. Out of many linguistic features, only graphology, phonology, syntax, and lexical features are analyzed in this research. The result shows that Instagram poems are mostly written in lower case letters in the same font. They also form free rhymed poems by using enjambment to break the sentences into several lines. The Instagram poets also chose their words carefully to create a specific meaning in the lines while creating a balanced emotion of word connotation.
\end{abstract}

Keywords: Stylistics, graphology, phonology, syntax, lexis, Instagram poems. .

\section{INTRODUCTION}

Instagram is a social networking website or platform which allows its users to share personal files including pictures, audio files, and blogs. Each user may upload as many photos or pictures as he or she desires within the terms and conditions applied on the platform. As in June 2018, Ashley Carman, wrote that Instagram just announced their achievement of one billion users within the average of 190 million active users per day (Carman, 2018). Among one billion users, many use Instagram as a media to share their creative work especially poems.
There are many definitions of poems, one of which, made by Robert Frost is "one where the emotion has found its thought and the thought has found the words" (Tiati, 2011). Whereas a poet defined by Cambridge Dictionary is "a person who writes poems" ("Poet", 2020). This means that anyone can write a poem to express his/her emotion and can call himself/herself a poet. He/she can publish the poem in any preferred media including Instagram. Nowadays, there are many poems posted on Instagram written by Instagram poets. These poets such as @rupikaur__ @poetryofdhiman @dikagustin @atticus @rmdrk and many more claim themselves as poets. Instagram poets have 
been recognized for their simplicity. A digital director of the Institute of Poetry and Poetics at Durham University, Dr. Eleanor Spencer-Regan, commented on "Instagram Poets", saying that their writings create a relatable sense with tone and vocabulary that talk about self-help or selfimprovement just like motivational quotes (Byager, 2018). This is why poems that are posted on Instagram are claimed to be relatable to the readers, especially to the millennials. Besides the content, Byager (2018) added that the language used by Instagram poets is simple and thus it helps them to always connect directly with their readers.

\section{LITERATURE REVIEW}

Stylistic has been used to analyze written work such as poems. Lilik Hidayati wrote Stylistic Analysis of William Wordsworth's Poem: "I Wandered Lonely as a Cloud" in 2015. The paper focuses on the lexico-syntatic patterns, figurative language, phonology, graphology, and morphology. Foregrounding patterns refer to the form of textual patterning which makes some features in the poem stand out for aesthetic purposes.

Another research written by Rabia Mahmood and Anila Jamil, entitled Stylistic Analysis of Holly Thursday I by William Blake in 2015, analyzed William Blake's poem entitled Holly Thursday I. It focuses on the lexico-syntatic patterns and choices, semantical, grammatical, graphological and phonological patterns. In their research Mahmood and Jamil found a dissimilarity between poetic and non-poetic language which is a means of defining literature.

Stylistics analysis can also be used to analyze Instagram caption and song lyrics. An undergraduate thesis entitled Stylistic Analysis of Beauty Cosmetic Advertising Posts in Instagram Captions in 2018 was written by Joy Samantha Suwondo. The object of her research is Instagram captions of beauty cosmetic advertisement posts. Instagram caption itself is a brief textual explanation about the photo or video posted by the Instagram users. This research uses Peter Verdonk's theory of stylistics, focusing on the graphological, phonological and lexical features and the result of using the linguistic features. The researcher analyzed the caption of five different cosmetics brands along with the responses of other Instagram users in the comment section.

Another undergraduate thesis from Universitas Gadjah Mada entitled 2AM's Song Lyrics: Stylistic Analysis was writen by Dinar Wahyu Kirana, a student of the Korean Language undergraduate study program in 2017. This research is an analysis of 2AM's song lyrics based on the sound, morphological, and semantic elements. The researcher also analyzed how the theme of sadness in these songs relates to the previous mentioned features.

\section{THEORETICAL FRAMEWORK}

In accordance with the objective of the research, stylistics theory is applied to analyze the data source which is Instagram poems. The poems are analyzed by using Verdonk and Simpson's stylistic theory focusing on its linguistic features such as graphology, phonology, syntactic, and lexical features.

The general definition of style by Verdonk is "a distinctive manner of expression, though whatever medium this expression is given physical shape" (2002, p. 3). Stylistics is "a method of textual interpretation in which primacy of place is assigned to language" (Simpson, 2004). There are two division of stylistics, the literary stylistic and linguistic stylistic. Paul Simpson explained that literary stylistics is an extension of practical criticism meanwhile the linguistic stylistics "seeks the creation of linguistic models for the analysis of texts - including those conventionally thought 'literary' and 'non-literary"' (2004). In other words, written texts can be analyzed by using linguistic stylistics. In a written text, language has "various forms, patterns and levels that constitute linguistic structure which are an important index of the function of the text" (Simpson, 2004, p. 2).

Stylistic analysis is the study of style to analyze expression in language to see the purpose and its effect (Verdonk, 2002). Therefore, stylistic analysis is applied to explore and get a better understanding of the creativity of a language used in 
a written text. In addition, Simpson gave his definition of stylistic as a method to interpret textual language in various forms, patterns and levels that establish linguistics structure (2004).

In stylistic studies, graphological deviation may affect meaning and produce aesthetic effects (Gómez-Jiménez, 2015). Graphology as defined by Wales is closely attached to the concept of word from dictionaries, manuals, and works of references in general including letters beyond the alphabet like punctuation marks and spacing (Gómez-Jiménez, 2015). In other words, graphology sees the aesthetic features of the poems such as the fonts and the size that are used. There are four aspects in graphology: spelling, punctuation, typography, and layout. Spelling is "the act of forming words correctly from individual letters (Hornby, 2010). Punctuation marks have many roles when they are put in the text. Say and Akman explained that "they can have a morphological role, a delimiting role, or a separating role, and also roles in the usage of capital letters as in to resolve ambiguities" (1998, p. 2). Typography and layout are mentioned in graphology as linguistic features because they collect the visual features of a language. In addition to the definition of typography and layout, Levenson who divided graphology into four aspects emphasizes typography as the use of italics for a variety of purposes, while his definition of layout is his concern with "the ability of readers to distinguish between poetry and prose 'without the benefit of typography”' (Finneran, 1997, p. 371).

Phonology focuses on the pronunciation of sounds in various contexts (Meyer, 2009). Every linguist uses different sound device or phonology tools to analyze a text. In speech, rhythmic patterns help listeners to get the sense of meaning from the strings of syllables (Lennard, 2005). In poetry, it is the freedom of poets to create the kind of beat or sense of feeling in their poems. Along with his explanation about forms, Lennard explained the relation between form and rhyming pattern. First, a free verse poem has no predetermined form but still has rhythms (Lennard, 2005). It is easier to analyze a free verse poem by taking notes of the beats and the rhyme since there is no fixed form of free verse poem.
Syntax is the rules about words which are combined to form phrases, clauses, and sentences (Nordquist, 2019). It also represents a speaker's knowledge of sentences and their structures. With the rules, in this case, the English rules of syntax, it creates meaning and describes the relationship between groups of words. People can create sentences through combining words. A sentence is "word or group of words that expresses a complete idea and that includes a subject and a verb" (Nordquist, 2019). There is a term, enjambment, in relation to grammar and poetry that poets often use to separate syntax of a sentence into two or more lines. Enjambment itself is "continuation of a sentence or clause across a line break" (Litchart, 2017). By using enjambment, a sentence does not make sense until it ends with punctuation marks.

The lexical feature deals with the use of a particular word which may influence the whole series of other words (Meyer, 2009). Regardless of the word classes, each word is related to one another. Lexical relation focuses on "characterizing the meaning of each word in terms of its relationship to other words" (Yule, 2010, p. 117). Therefore, poets try to choose their words carefully.

\section{METHODS}

The method used in this research is library and online research. The data for this research are the lines in the poems containing linguistic features which are obtained from the poems posted on Instagram.

\section{Methods of Data Collection}

The data from this research were obtained from poems of three different Instagram-poets, @rupikaur_@poetryofdhiman @rmdrk. Among many poems they have posted on Instagram, this research only analyzed five most liked poems from each poet. The researcher began collecting the poems by opening a website called topnine.co which calculates each pictures posted by each user in a year and provides the users with top nine liked pictures. After accessing the website, the researcher typed the username of each poet. The page then 
showed nine most-liked poems from each username. Thus, the first five poems displayed became the data source for this research. The poems then were downloaded into the researcher's hard drive. However, this website only provided nine poems in the form of one big picture instead of individual poems. As a result, the researcher typed the total of fifteen poems into one file. The researcher then sorted the poems from each poet based on the number of likes on the poem from the highest to the lowest. From the list, the researcher coded the poems with r1-r5 for Rupi Kaur's, h1-h5 for Dhiman's, and d1-d5 for Drake's.

\section{Methods of Data Analysis}

After the data were collected, the poems were analyzed by using the theory proposed by Peter Verdonk and Paul Simpson on stylistic features including its foreground elements. Then, the theories of stylistic and linguistic features were applied to analyze each of the poems thoroughly. Each line of the poems was observed based on the linguistic aspects of graphology, phonology, syntax, and lexis.

\section{RESULTS AND DISCUSSION}

The data of this research, taken from Instagram poems, are analyzed using stylistics theory proposed by Verdonk and Simpson. The analysis focuses on the linguistic features of the poems including the graphology, phonology, syntax and lexical features. There are three Instagram poets, Rupi Kaur, Dhiman, and R.M. Drake, whose poems were analyzed in this research. Using five most liked poems from each poet, the analysis was conducted to understand the style of Instagram poems.

\section{Graphology}

In terms of spelling, none of the poets used different kinds of spelling or deliberately misspelled the words. There are no words that can indicate whether they wrote the poems based on British English or American English spelling. In punctuating, Kaur did not use any punctuation marks while Dhiman and Drake used few quotation marks, period, coma, and one question mark. As for typography and layout, all poets used the same font type except for Drake, who used a different font in one of his poem. For the particular poem, d5, he used typewriter font. In capitalization, only one out of 15 analyzed poems used capitalization and this was written by Drake. Only Rupi Kaur wrote three out of 29 lines in italics, while the others did not. Lastly, the text alignments mostly used by the three poets are left align with only one poem by Drake with center align.

"but what if i lose them?"

"but darling, what if you lose yourself?"

In the example above, Dhiman used three punctuation marks: quotation marks, a comma, and question marks. With the quotation marks, readers can tell that the poem is a conversation between two people. It is written in left align as conversations are usually written.

\section{Phonology}

There are only five out of 15 poems analyzed rhymed. The other ten poems use free rhyme and have various beats. Drake's poems have the longest beats among the other poems with 13 beats in poem d3 followed by Kaur with 12 beats in poem r2 and r3. Other than the one-lined poem, d3, Drake wrote less than 11 beats. Meanwhile Dhiman prefers to write poems with no more than 9 beats.

you are slowly growing

but you are still growing

and that is enough

Among all fifteen poems, there are two types of rhyme that are found in this research. The first is the perfect rhyme with word to word similarity. This type of rhyme is found in poem h5, r1, and $\mathrm{r} 2$. The second is the similarity of phonetic sounds produced in each line. This rhyme is found in poem h2 and d1. The word 'them' and 'yourself' in poem $\mathrm{h} 2$ share the same [e] sound. 


\section{Syntax}

The words are categorized based on the structure they belong to. Kaur seems to use more predicators in her poems than Dhiman and Drake. She used two predicators in two different sentences, which makes the number of predicators used is higher than the subjects. On the contrary, Drake used only one predicator in a complex sentence in poem $\mathrm{d} 1$. In terms of the complement, not all predicators need complement, just like in Kaur's poem $\mathrm{r} 4$ and $\mathrm{r} 5$ and Dhiman's poem h4. Thus it makes the number of complement lower than the number of predicator. Besides the number of adjunct shows that the adjunct is optional and the three poets decided to use simple sentences consisting of only subject and predicator in their poems. As for enjambment, Rupi Kaur used enjambment more often than Dhiman and Drake. However, when the number of enjambment is compared to the number of sentences and lines, they share a similar number of enjambment. All of the poets use line breaks in their poems as seen in each liked poems in 2018.

"we all need someone to go home to.

someone to fight for and someone who'll

give us meaning in a meaningless world."

In poem $\mathrm{d} 1$, the second sentence after the first period does not have subjects. The word 'someone' in the sentence is not considered as a subject because it is a continuation of the previous statement. This poem can be fragmentized into three complements. The first part is "we all need someone to go home to" followed by "we all need someone to fight for", and finished with "we all need someone who'll give us meaning in a meaningless world". Therefore, the poem only has one subject which is 'we'. And this poem is also written using enjambment.

\section{Lexical}

The number of verbs used by each poet is the highest among the other word classes. The verbs that are written twice are also counted two times. Similar to the analysis of syntax, the verb is the predicator which is a component used in the poem to complete the sentence. Without a verb, the sentence does not have any motion. The number of adjective used is approximately the same as the number of the nouns. The adjective modifies the noun, thus the poets decided to make the noun even more specific with the adjective. As for adverbs, they modify the adjectives, verbs or other adverbs but are rarely used.

(4)

\section{(r5)}

when my daughter is living in my belly

i will speak to her like

she's already changed the world

she will walk out of me on a red carpet

fully equipped with the knowledge

that she's capable of

anything she sets her mind to

In the fifth line of the poem $\mathrm{r} 5$, there is the word 'red' acting as an adjective and 'carpet' as a noun. The adjective 'red' is used to describe the 'carpet'. The red carpet itself has existed since ancient Greek. Sonnet Stanfill, a senior curator at the Victoria \& Albert Museum explained in a BBC interview that, "There's a certain synergy about the red carpet - that was traditionally to welcome royalty - now welcoming film royalty" (Baker, 2016). Regardless of how red carpet relates more to the award shows, the red carpet is still considered as a symbol of luxury and royalty. In other words, it is a hope for her daughter to be rich of knowledge in order to be able to change the world.

\section{CONCLUSION}

The purpose of stylistics study is to analyze the style used in written art. This research is conducted on the linguistic features found in poems written by Rupi Kaur, Dhiman, and R.M Drake. Poems written by Rupi Kaur, Dhiman, and Drake are the focus of this analysis. From many poems each poet wrote in 2018, five most liked poems were analyzed. With the total of 15 poems, the researcher analyzed the poems by comparing each linguistic feature used in the poems. There are four linguistic features that became the main focus of this analysis which are graphology, phonetics, syntax, and lexical features. 
The similarities of these Instagram poems are the use of lower case letter; mostly left aligned, with no more than 13 beats of free rhyme in present tense and the word-choice create balance emotion of word connotation. The differences can be found not only within the poets but also in each of their own poems. It might look similar to one another, but each poem has its own style.

In conclusion, the use of linguistic features in Instagram poems is to create a style in order to entertain the readers. Instagram poems are written in such ways to create visually beautiful poems with its fonts, rhyme, length, and diction. Moreover, this analysis is limited to only four linguistic features whilst there are still other features that can be explored. Therefore, the researcher would like to encourage future researchers to analyze in depth other features of linguistics and or use other theories to analyze Instagram poems.

\section{REFERENCES}

Baker, L. (2016, February 22). Culture - where does the red carpet come from? Retrieved March 4, 2020, from

http://www.bbc.com/culture/story/20160222where-does-the-red-carpet-come-from.

Byager, L. (2018, October 19). Roll your eyes all you like, but Instagram poets are redefining the genre for millennials. Retrieved April 5, 2019, from https://mashable.com/article/instagrampoetry-democratise-genre/\#rrJij6A01sqw.

Carman, A. (2018, June 20). Instagram now has 1 billion users worldwide. Retrieved April 5, 2019, from https://www.theverge.com/2018/6/20/174844 20/instagram-users-one-billion-count.

Dhiman [poetryofdhiman]. (2018, November 03). [make room in your heart]. Retrieved from https://www.instagram.com/p/Bptm6waFTTi/.

Dhiman [poetryofdhiman]. (2018, December 24).

[do not lose yourself in trying to keep someone else]. Retrieved from https://www.instagram.com/p/BrvUymRhb_V /.
Dhiman [poetryofdhiman]. (2018, December 25). [the right ones do not leave]. Retrieved from https://www.instagram.com/p/Brz3rlJhgWE/.

Dhiman [poetryofdhiman]. (2018, December 27). [you are slowly growing]. Retrieved from https://www.instagram.com/p/Br3B_pxBCjF/.

Dhiman [poetryofdhiman]. (2018, December 30. [do not let it consume you] Retrieved from https://www.instagram.com/p/BsAvNOLHMz $\mathrm{Z} /$.

Drake, R. M. [rmdrk]. (2018, Januari 07). [Moon Theory is available in stores nation wide and Amazon.com \#rmdrk]. Retrieved from https://www.instagram.com/p/Bdp7JiaA6dp/.

Drake, R. M. [rmdrk]. (2018, February 02). [the four book bundle for $\$ 12$ is ALMOST GONE!!!]. Retrieved from https://www.instagram.com/p/BeqfDSZg1dn/.

Drake, R. M. [rmdk]. (2018, April 22). [always, my sweet people.]. Retrieved from https://www.instagram.com/p/Bh2UOEMAdU $\mathrm{b} /$.

Drake, R. M. [rmdrk]. (2018, August 21). [new bundle coming in November, xoxo]. Retrieved from https://www.instagram.com/p/BmvphQNgvoo /.

Drake, R. M. [rmdrk]. (2018, November 24). [Update: only 500 bundles left]. Retrieved from https://www.instagram.com/p/BqjL8w9H7nF/.

Enjambment - Definition and Examples. (2017, May 5). Retrieved from https://www.litcharts.com/literary-devicesand-terms/enjambment.

Finneran, R. J. (1997). The stuff of literature: Physical aspects of texts and their relation to literary meaning by E. A. Levenson. Text, 10, pp. 369-371

Gómez-Jiménez, E. (2015). An introduction to graphology: Definition, theoretical background and levels of analysis. A Journal of English and American Studies, 51, 71-85.

Hidayati, L. (2015). Stylistic Analysis of William Wordsworth's Poem: "I Wandered Lonely as a 
Livia A. Wiadji, Sharifah Hanidar / Linguistic Stylistic Analysis of Instagram Poems | 61

Cloud"(Unpublished Master's thesis), UIN

Sunan Ampel, Surabaya, Indonesia.

Hornby, A. S. (2010). Oxford advanced learner's dictionary, 8th edition. Oxford: Oxford University Press. Print.

Kaur, R. [rupikaur_]. (2018, August 07). [page 237 from \#thesunandherflowers]. Retrieved from https://www.instagram.com/p/BmKMCIsAWy $\mathrm{K} /$

Kaur, R. [rupikaur_]. (2018, September 14). [page 63 from \#milkandhoney]. Retrieved from https://www.instagram.com/p/Bnr4VPOHwN $\mathrm{Q} /$

Kaur, R. [rupikaur_]. (2018, November 19). [page 87 from \#thesunandherflowers]. Retrieved from https://www.instagram.com/p/BqWCZRqnhv $\mathrm{z} /$

Kaur, R. [rupikaur_]. (2018, November 26). [nuh uh honey page 136 from \#milkandhoney]. Retrieved from https://www.instagram.com/p/BqoLfrXncEw/

Kaur, R. [rupikaur_]. (2018, December 12). [mountains]. Retrieved from https://www.instagram.com/p/BrRDStPHZbf/

Kirana, D. W. (2017). 2AM's Song Lyrics: Stylistic Analyze (Master's thesis, Universitas Gadjah Mada, 2017). Yogyakarta.

Lennard, J. (2005). The poetry handbook ( $2^{\text {nd }}$ Ed.). Oxford University Press.

Mahmood, R., \& Jamil, A. (2015). Stylistic analysis of Holly Thursday I by William Blake. International Journal of English Language and Linguistics Research, 3(6), 46-52.

Meyer, C. F. (2009). Introducing English Linguistics. Cambridge University Press.
Nordquist, R. (2019, January 19). What Is syntax? Retrieved May 15, 2019, from https:/www.thoughtco.com/syntax-grammar1692182

Nordquist, R. (2019, July 25). Sentence definition and examples in English grammar. Retrieved May 7, 2020, from https://www.thoughtco.com/sentencegrammar-1692087

Poet. (n.d.). In Cambridge Dictionary. Retrieved from https://dictionary.cambridge.org/dictionary/e nglish/poet

Say, B., \& Akman, V. (1998). An information-based treatment of punctuation in discourse representation theory. Bilkent University. Retrieved from https://pdfs.semanticscholar.org/c5bf/33ac80c 172b721bb15e68540d543fbea5fde.pdf

Simpson, P. (2004). Stylistic: A resource book for students. Rouledge.

Suwondo, J. S. (2018). Stylistic analysis of beauty cosmetic advertising posts in Instagram captions (Unpublished Master's thesis), Sanata Dharma Univeristy, Yogyakarta, Indonesia.

Tiati. (2011, March 16). What is poetry? 50 definitions and counting. Retrieved May 7, 2020, from http://www.poetinthecity.co.uk/what-ispoetry-50-definitions-and-counting/

Verdonk, P. (2002). Stylistics. Oxford University Press.

Yule, G. (2010). The study of language (Fourth ed.). Cambridge University Press 